\title{
Proyecto educativo: Ambientación artística del Salón del Libro Infantil y Juvenil
} \section{Artistic setting of the Children and Youth Book Fair}

\author{
María Begoña Paz García, Iciar Ezquieta Llamas, Cristina Varela Casal \\ Universidad de Vigo
}

\begin{abstract}
Resumen
El Salón del Libro Infantil y Juvenil de Pontevedra es un proyecto sociocultural para promocionar lengua gallega y la animación a la lectura entre escolares gallegos. Uno de los pilares del proyecto es la transformación artística, interactiva y educativa del espacio expositivo. En este contexto nace una colaboración entre las artistas encargadas de la ambientación y las docentes de un CEIP participante, materializándose en la creación de la unidad didáctica "Salón del Libro" cuyo objetivo principal es implicar a la escuela en un proyecto significativo haciendo partícipes al alumnado de sexto de primaria en el diseño de la ambientación.

Palabras clave: arte, aprendizaje por experiencia, aprendizaje en grupo, relación escuela-sociedad.
\end{abstract}

\section{Abstract}

The Pontevedra Children's Book Fair is a sociocultural project that promotes Galician language and encourages reading among Galician students. One of the cornerstones of the project is the artistic, interactive and educational transformation of the exhibition space. In this context it emerges a collaboration between the artists in charge of the setting and the teachers of a primary school involved, creating the teaching unit Book Fair, whose main objective is to get the school involved in a significant project and the sixth-grade students in the design of the setting.

Keywords: art, learning by experience, group learning, school-society relationship.

\section{Introducción}

El Salón del Libro Infantil y Juvenil de Pontevedra es un proyecto sociocultural que tiene como objetivo la promoción de la lengua y literatura gallega, así como la animación a la lectura. El Salón, con sede en el Pazo da Cultura, ofrece a lo largo de tres semanas una amplia programación cultural (presentaciones de libros, cuenta cuentos, teatro, música, talleres de artes plásticas, ...) destinada en horario lectivo a los centros escolares y por las tardes y fines de semana al público en general. Este proyecto con un bagaje de 18 ediciones tiene una amplia repercusión en la comunidad educativa, social y cultural de Galicia.

La participación de los centros escolares se centra en la creación de una producción artístico-literaria (libro, libro-escultura, libro-juego) donde las historias e ilustraciones abordan la temática que cada año es diferente (la naturaleza, el mundo que queremos, el amor, el miedo, la máquina...). Los temas planteados permiten trabajar contenidos educativos como la educación en valores, educación ambiental, para la salud, educación emocional, etc. Estas creaciones conforman la exposición principal del Salón donde conviven con otros contenidos culturales como son la exposición de MI Ilustra diseñada específicamente por el alumnado del Máster de Ilustración de la Universidad de Vigo, o exposiciones de ilustradores/as profesionales como Jacobo Fernández Serrano, Kiko da Silva, Luis Davila "El Bichero", Óscar Villán, entre otros.

Otro de los aspectos que dan carácter al Salón del Libro es la ambientación artística que año tras año transforma la sala de exposiciones en un espacio diferente que despierta la imaginación de los/as visitantes. Para ello un grupo de creadores/as de diferentes campos (artes plásticas, arquitectura, ilustración, diseño y educación) de la Asociación Socioeducativa Cultural y Escuela de Tiempo Libre Paspallás desarrollamos un proyecto artístico basado en estrategias pedagógicas, lúdicas y creativas.

El Salón está compuesto de diferentes espacios con usos y necesidades específicas, estos son: la sala de exposiciones, la biblioteca, las salas de cuenta-cuentos, las zonas de talleres, la zona de espectáculos, la sala de meriendas, el rincón de presentaciones de libros y la bebeteca.

El proyecto de la ambientación parte de una idea estética original, basada en contenidos educativos y que se desarrolla a través de estrategias propias del juego fomentando así la interacción de los/as usuarios /as con un escenario creado específicamente para la participación y la colaboración.

Durante más de diez años creando la ambientación artística del salón hemos tenido la oportunidad de conocer el trabajo realizado por docentes y alumnado de diferentes centros escolares lo que ha abierto vías de colaboración.

Este proyecto nace del diálogo con dos docentes del CEIP do Carballal de Marín quienes perciben la necesidad de darle el valor académico que tiene el realizar este tipo de proyectos extracurriculares, entendiendo que deben tener una réplica en el curriculum y en la evaluación formativa del alumnado. Partiendo de 
estas premisas se plantea la posibilidad de desarrollar un trabajo por proyectos basado en la creación de la ambientación del Salón del Libro y en consecuencia se diseña una unidad didáctica orientada al alumnado de sexto de primaria para la ambientación del Salón del Libro 2016, un proyecto interdisciplinar de expresión plástica, lengua gallega, matemáticas y ciencias naturales con una dimensión sociocultural de relevancia. Para llevar a cabo el proyecto se plantea una metodología de trabajo colaborativo (artistas-educadoras-educandos)

Desde un enfoque artístico-educativo esta iniciativa es una importante oportunidad para dar a conocer el ámbito profesional de las artes plásticas entre los/as niños/as y despertar inquietudes e intereses relacionados con la creación plástica y visual.

\section{Objetivos}

Este proyecto colaborativo tiene como objetivo principal fomentar el aprendizaje significativo a través de un trabajo por proyectos interdisciplinar que tiene como eje conductor la expresión plástica, y como objetivos específicos que los/as niños/as lleven a cabo una intervención de ambientación dentro del Salón del Libro Infantil y Juvenil 2016, desarrollando todas las fases del proceso creativo desde la elaboración de la idea hasta su materialización en una producción que será expuesta en un contexto sociocultural.

\section{Metodología}

La metodología empleada se enmarca en la acción pedagógica sustentada en el trabajo cooperativo y en la toma de decisiones consensuadas, una propuesta diversificada que permita adaptarse a las individualidades del alumnado.

Se plantea un enfoque constructivista donde el conocimiento se concibe como una construcción que realiza el niño/a en su interacción con el medio (Piaget, 1971). La actividad constructiva parte de los esquemas previos que este posee teniendo en cuenta que el conocimiento se modifica en la medida en que incorporamos nuevos elementos. Por ello es fundamental pautar unas sesiones de iniciación.

El aprendizaje significativo se entiende como un proceso de relación con sentido entre las nuevas ideas y las que posee el alumnado (Ausubel, 1976). Por un lado revierte en una memorización comprensiva y por otro asegura la funcionalidad de lo aprendido, de modo que se adapte a las situaciones futuras. Es importante conectar con las necesidades del alumnado, son su experiencia y contexto programando actividades que establezcan esta relación. El docente y en este caso el artista son quienes facilitarán esa relación.

Este modelo metodológico responde también al de "proyectos de trabajo" segundo Arias (2009) que se define como un estrategia de organización basada en el tratamiento de la información de forma conjunta, estableciendo relaciones entre los contenidos y el enfoque globalizado o interdisciplinario que favorece la construcción del conocimiento y consecución de las competencias básicas, de forma que estos aprendizajes sean significativos e contextualizados.
El trabajo el cooperativo tal y como plantean Johnson, Johnson y Holubec, (1999) se tienen en cuenta unos elementos esenciales: interdependencia positiva para llevar a cabo la tarea asignada y asegurarse de que todas las personas del grupo también lo hacen; interacciones cara a cara de apoyo mutuo entre los miembros del grupo, se consultan, comparten recursos, intercambian materiales e información, comentan sus progresos, se proponen modificaciones, etc., en un clima de responsabilidad, interés, respeto y confianza; responsabilidad personal individual.

Para llevar a cabo esta metodología colaborativa entre artistas, docentes y alumnado se elabora conjuntamente un plan de trabajo viable adaptando los ritmos de los dos ámbitos: el educativo y el profesional. Es importante destacar que paralelamente a la intervención educativa se está desarrollando la fase de montaje en el Salón por lo que los dos procesos el educativo y el profesional conviven. Este espacio de contagio permite discutir sobre una realidad concreta, realizando reuniones de trabajo previas a la intervención con las docentes para diseñar y organizar las fases del proyecto, las actividades y su temporalización.

El proyecto se desarrolla a lo largo de un mes y medio en el que se realiza una actividad inicial de toma de contacto con el alumnado. El seguimiento del proyecto se desarrolla a través de diferentes vías de comunicación como son reuniones con las profesoras, visitas al espacio de taller y mails, para poder orientarles en los momentos de bloqueos y divergencias propias del proceso creativo.

\section{Participantes}

30 alumnos y alumnas de sexto de primaria, dos profesoras y tres artistas-docentes.

\section{Instrumentos o Materiales}

Los instrumentos y materiales empleados son variados, adecuados para cada una de las fases de trabajo: un plano de situación de la sala de exposiciones para reconocer el espacio antes de su intervención, posibles recorridos, medidas y distribución de los espacios; un cuaderno de campo para la recogida de ideas y bocetos (individual); fichas explicativas de los espacios a intervenir con una descripción detallada de sus características: el dibujo como herramienta de registro de información para plantear las ideas; textos explicativos para detallar los detalles de construcción y como contenido artístico (poema-adivinanza); la construcción de una maqueta para visualizar las dimensiones de la intervención y plantear soluciones adaptadas a la realidad; el diccionario para la revisión de las creaciones literarias.

\section{Procedimiento}

Al ser un proyecto planteado desde dos vías se combinan dos procesos de trabajo, por un lado, el artístico-profesional y por otro el educativo. Para trasmitir de forma didáctica a los/as niños/as cómo es el proceso de creación de la ambientación del Salón, las directoras artísticas realizan un informe detallado donde se describe en qué consiste el trabajo de ambientación, explicando las fases y los aspectos a tener en cuenta: la idea estética, los contenidos educativos implícitos, los 
espacios y sus características, la edad de los/as usuarios/as, la durabilidad de los materiales, el montaje y una temporalización indicando la secuencia de las tareas con sus tiempos estimados de ejecución.

Debido a que nuestra labor artística se complementa con la docencia en la materias de Didáctica de la Artes Plásticas y Visuales en el grado de Infantil y Primaria de la Facultad de Ciencias de la Educación y del Deporte de Pontevedra, diseñamos una propuesta de actividades enfocadas a abordar los contenidos propios del proyecto como son: la escala y las dimensiones, la maqueta como forma de representación tridimensional, el dibujo como herramienta comunicativa, la manipulación y experimentación de materiales (durabilidad y resistencia), la ilustración, espacio y distribución, la creatividad...Estas documentación les servirá a las maestras para elaborar los contenidos de la unidad didáctica que a continuación se detalla.

La primera tarea "Conocemos el Salón" inicia con una actividad que consiste en la visita del alumnado a la sala de exposiciones del Pazo da Cultura de Pontevedra donde también participan las artistas, las docentes y el responsable del mantenimiento de la sala del Pazo. Se les entrega un plano para reconocer el espacio y orientarse en sala. También realizan otras actividades como tomar referencias con el cuerpo para calcular las dimensiones y poner nombre a los espacios recorridos. Se aprovecha la visita para presentar el tema del Salón 2016 que lleva como título "Canta Bichería". Se lleva al grupo a una sala de reuniones y se explica el proceso seguido para la creación de la ambientación analizando imágenes de años anteriores, y mostrando materiales de los procesos creativos de otras ediciones (maquetas, cuadernos de artista, pruebas de materiales). En esta sesión se asientan las bases del proyecto y se comparte con el alumnado la responsabilidad de crear una intervención-juego.

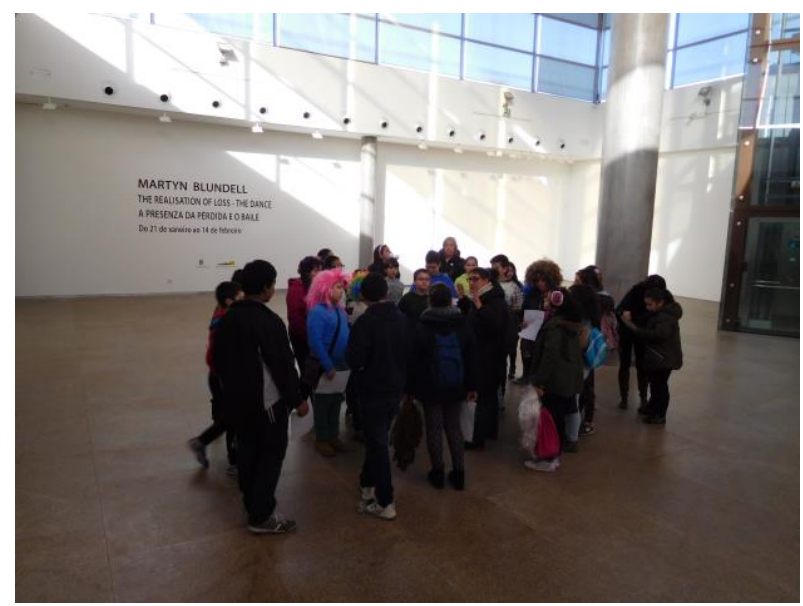

Figura 1. Visitando la sala de exposiciones

El trabajo creativo continúa en el aula, las docentes aprovechan la visita al pazo para profundizar en contenidos curriculares a través de dos actividades. En la actividad 2 "Comprobación de los tamaños a través del plano" se ordenan las mediciones realizadas de mayor a menos y se calcula el valor real de $1 \mathrm{~cm}$ en el plano, se comparan medidas reconociendo formas espaciales y se relacionan elementos a través de escalas sencillas. En la actividad 3 "Maqueta del Salón" se realiza una maqueta de la sala de exposiciones a escala 1:100 iniciándose en las medidas y la proporcionalidad, dibujando sobre cartón la planta para luego reconstruir el espacio físico real sobre el que van intervenir.

En una segunda tarea titulada "Propuesta de la ambientación para un espacio del Salón del Libro" se plantea una actividad que consiste en dibujar bocetos con las ideas para la ambientación, para ello, primero escogen el espacios a ambientar y después analizan las fichas diseñadas con las características de cada espacio. Los dibujos realizados (papeleras intervenidas, la entrada como una selva, la pared de juego de camuflaje...) se explican oralmente en gran grupo. Este material es revisado por las artistas y se propone una línea de continuidad mezclando ideas recogidas de diferentes dibujos. Algunas de las ideas que no se pueden realizar por la premura de los tiempos se anotan para futuras ediciones, como son incorporar una señalética divertida con dibujos o elementos en volumen o decorar las papeleras.

En una sesión grupal los/as alumnos/as deciden realizar una intervención en el espacio de la sala de meriendas a modo de juego de adivinanzas que parte de la idea del camuflaje combinando textos en gallego y dibujos.

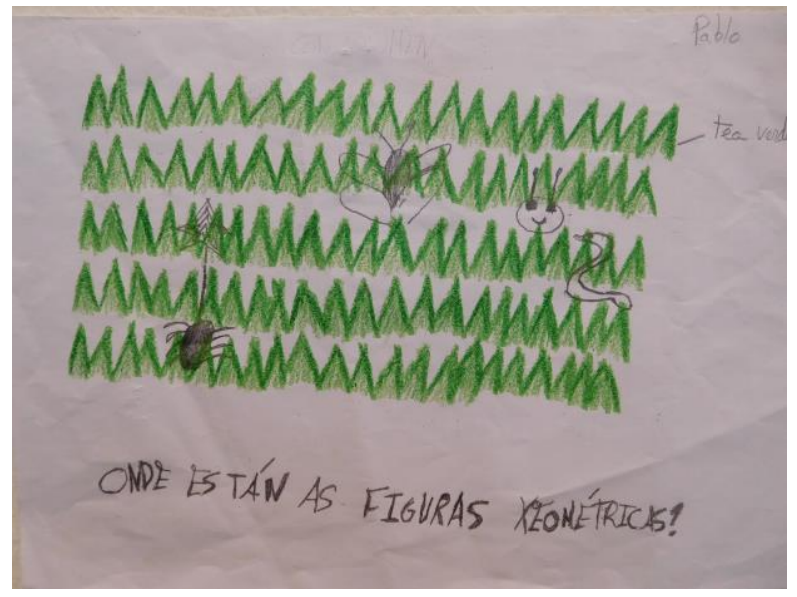

Figura 2. Boceto que introduce la idea de camuflaje

La tarea tres "Ambientación de un espacio" se compone de cuatro actividades: bichos camuflados, elaboración de dibujos, composición e instrucciones del juego. En gran grupo se visionan imágenes de animales camuflados en la naturaleza analizando formas, colores, texturas... con esta información los/as niños/as dibujan sus propuestas de bichos para colocar en el juego. Se revisan las medidas de la pared y se plantea una composición con tres paneles donde colocar las tres adivinanzas, con tres animales distintos. Para facilitar la ejecución de la intervención se les envían las medidas de las planchas de madera $(60 \times 240 \mathrm{~cm})$ donde irán las adivinanzas con sus textos y dibujos. En el taller del Salón se pintan los soportes para avanzar el trabajo de montaje y se les envía una muestra de la gama cromática y una foto la pared.

En el aula se realiza una plantilla a escala para plantear la composición y decidir los tamaños y el número de las 
imágenes que necesitan. Los dibujos seleccionados (mariquitas, orugas, mariposas, flores y lechugas) se imprimen distintos tamaños y se recortan.

En la clase de lengua se trabaja con el texto creando las instrucciones del juego y elaborando las adivinanzas para ellos se buscan palabras que tengan rima consonante, se realizan pareados y se debate en grupo cuáles son los más adecuados para el juego, de esta forma se elaboran los poemas finales, como por ejemplo: Ahí están as xoaniñas, subindo aos amorodos. Elas son tan pequeniñas que andan moi amodo. Cantas podes atopar, unha, dúas, tres ...ou catro?
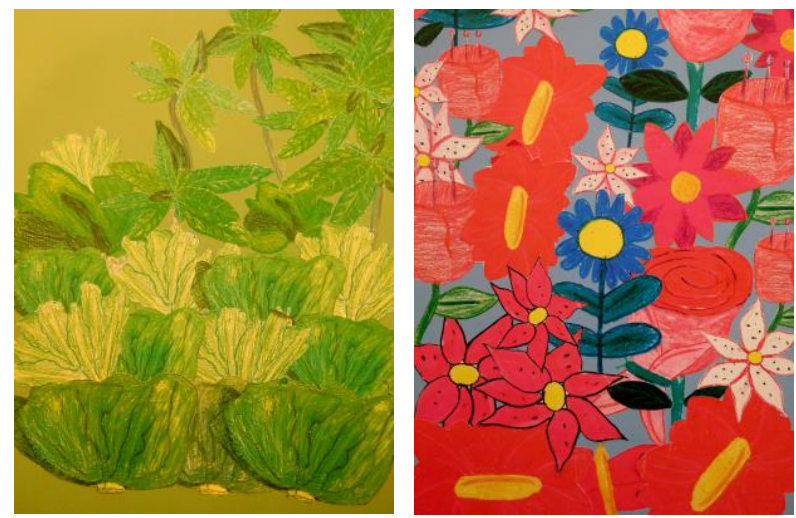

Figura 3. Dibujos de la intervención

Finalmente, los textos van en la parte superior de la composición y están realizados en vinilo de corte, a continuación, los dibujos se montan superpuestos unos sobre otros jugando con la ocultación de los bichos (mariposas, gusanos, mariquitas). El trabajo de montaje lo realizaron las docentes al ser inviable traer a los/as alumnos/as.

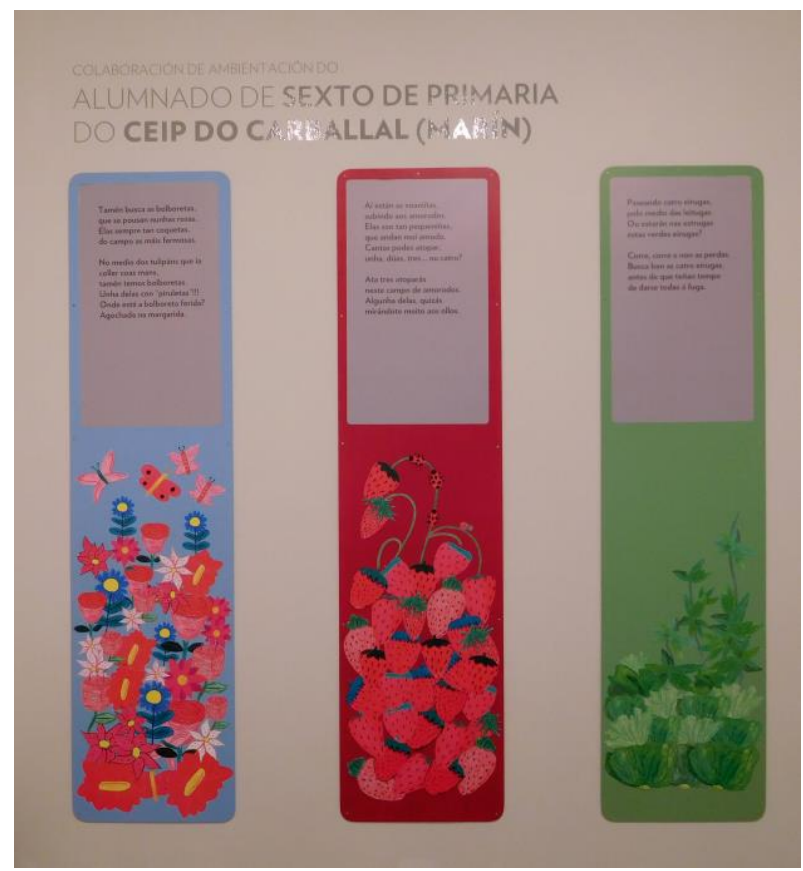

Figura 4. Ambientación terminada

\section{Resultados}

El trabajo desarrollado en este proyecto de colaboración se refleja en tres resultados: a nivel curricular en la elaboración de una unidad didáctica titulada "Ambientación del Salón", como transmisión de conocimientos y aprendizaje significativo en la creación de una adivinanza-juego que formó parte de la ambientación artística el Salón del Libro Infantil y Juvenil de Pontevedra 2016 por el que pasaron una media de 30.000 personas, y por último, la transferencia de la experiencia a otro ámbito educativo a través del encuentro entre los/as alumnos/as de sexto de primaria con el alumnado de $2^{\circ}$ curso del grado de Educación Primaria de la facultad de Ciencias de la Educación y del Deporte de Pontevedra.

El proyecto a través de su concreción curricular en una unidad didáctica con sus actividades, contenidos, metodología, estándares y criterios de evaluación, fundamenta el valor pedagógico que debe tener toda intervención educativa, así como la importancia de incorporar experiencias significativas y contextuales como parte del curriculum.

La ambientación poema-juego visual de adivinanzas respondió a las expectativas que se tienen de una ambientación interactiva, los/as niño/as que visitaban el Salón se paraban a leer y buscar los animales camuflados, a contarlos, a identificarlos, se divertían. El poema-visual también se utilizó como recurso didáctico por los/as monitores/as de sala encargados de hacer las visitas guiadas a los centros escolares.

El resultado a nivel estético del poema-juego fue bien valorado por ser una composición original, donde se trabajó el equilibrio en la composición de cada panel y en su integración en el espacio, haciendo un estudio de color y análisis de las formas que abordaban contenidos temáticos, empleando estrategias creativas como el camuflaje tanto en el poema como en las creaciones plásticas .

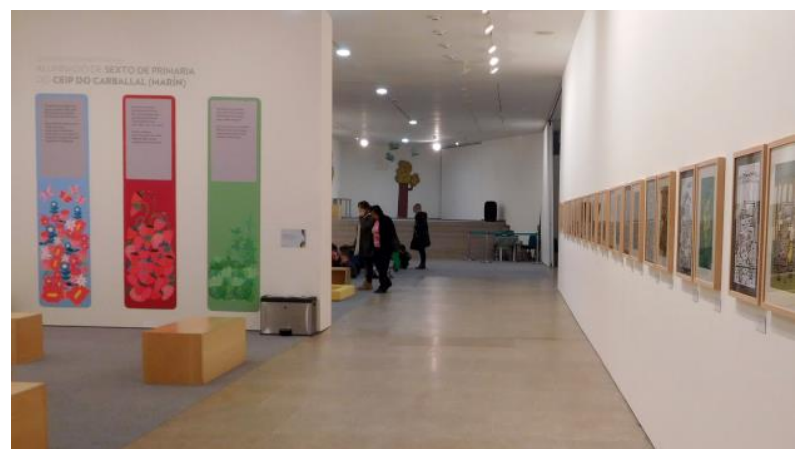

Figura 5. Visión general de la sala de exposiones

En cuanto a la visita del alumnado a la Universidad hay que destacar que para ambos colectivos fue una experiencia muy enriquecedora. Los/as niños/as a través de una presentación visual y explicaron el proyecto desde su perspectiva valorando todo el trabajo que hay detrás de un pequeño proyecto. Por su parte, los/as futuros/as docentes conocieron en primera persona una experiencia educativa de colaboración y socialmente relevante. 


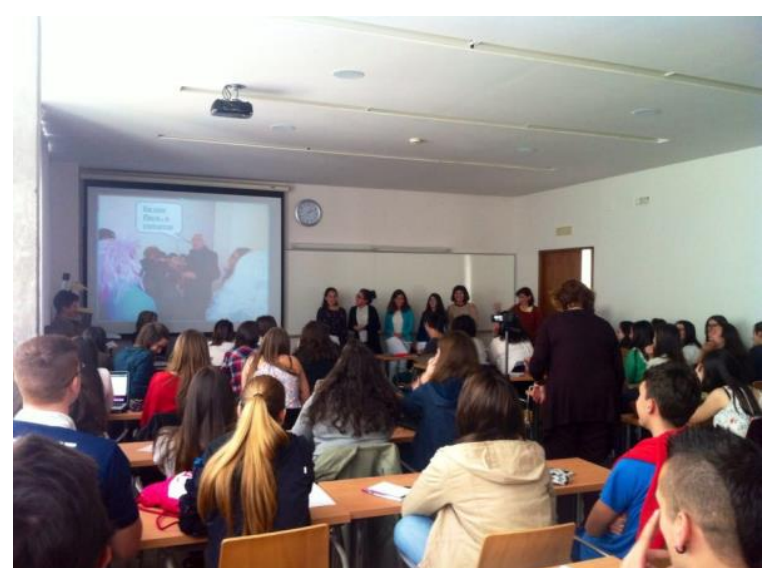

Figura 6. Visita del alumnado a la universidad

\section{Discusión}

Gracias a este proyecto que nace de una propuesta artística, la educación plástica y visual toma presencia dentro y fuera de la escuela abriendo vías de comunicación que permiten transferir la experiencia educativa en lo social y viceversa.

La colaboración de artistas en el aula revierte en la motivación del alumnado, estos se sienten valorados/as estableciéndose una relación de corresponsabilidad entre ambas partes. Como artistas y educadoras la experiencia directa con la escuela es fundamental para poner práctica la teoría pedagógica y poder desarrollar nuevas líneas de investigación.

A través de la expresión plástica los/as niños/as en los/as creadores/as de su propio aprendizaje comprendiendo de forma práctica y experiencial las relaciones que se dan entre los contenidos, en este caso de plástica, lengua, ciencias naturales y matemáticas.

El trabajo en grupo permite desarrollar habilidades inter-intra personales que se reflejan en soluciones combinadas y reformuladas entre todos/as así como un repartición de tareas eficaz y eficiente.

Plantear un proyecto artístico con un fin concreto y unos tiempos de ejecución determinados, motiva al alumno/a quien a través de la experimentación aprende a reconocer las frustraciones propias del proceso creativo, pero también a superar obstáculos y plantear soluciones.

Es fundamental establecer lazos directos entre la universidad y la escuela, generar espacios de conexión para el diálogo e intercambio de experiencias con el fin de acercar la realidad educativa gallega a sus futuros/as docentes.

En conclusión, estas experiencias que nacen del interés mutuo por aprender y enseñar entre colectivos de ámbitos diferentes son las que realmente dejan un recuerdo, un aprendizaje, despiertan una inquietud en las personas, sea artista, docente o alumno/a.

\section{Referencias}

Arias Correa, Azucena et al. (2009). O traballo por proxectos en infantil, primaria e secundaria. Santiago de Compostela: Xunta de Galicia.

Ausubel, D. (1976). Psicología educativa. Un punto de vista cognoscitivo. México: Ed. Trillas.
Piaget, J. (1971). Psicología y pedagogía. Barcelona: Ariel.

Johnson, D; Johnson, R.; Holubec, E (1999). El aprendizaje cooperativo en el aula. Barcelona: Paidós.

\section{Agradecimientos}

Agradecer la labor docente de Milagros Paz García y María del Rosario Martínez Epifanio al fomentar la educación artística en todos los proyectos que desarrollan. A la concejala Anxos Riveiro del ayuntamiento de Pontevedra y a la directora del Pazo da Cultura Pilar Portela por apoyar en estas iniciativas que vinculan arte, educación y cultura. A la asociación socioeducativa y cultural Paspallás y Escuela de Tiempo Libre por crear proyectos de arte y educación. 